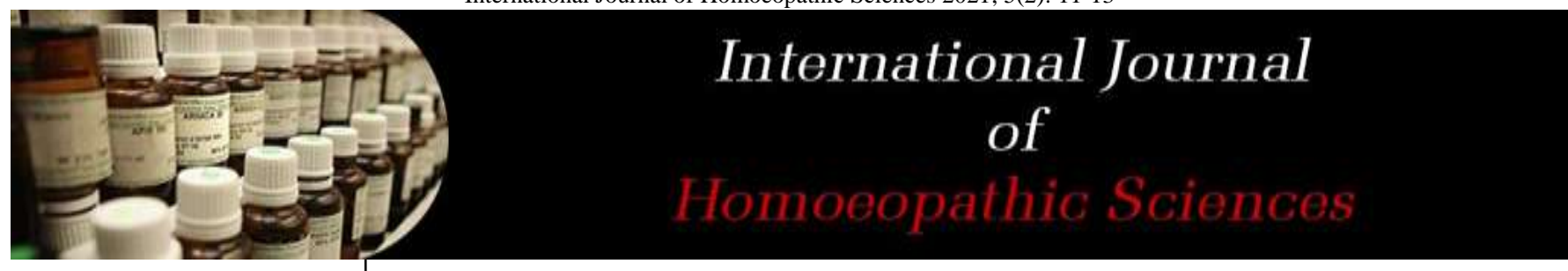

E-ISSN: 2616-4493 P-ISSN: 2616-4485 www.homoeopathicjournal.com IJHS 2021; 5(2): 11-13

Received: 10-01-202

Accepted: 13-02-2021

Dr. Tanupriya Bhardwaj Assistant Professor, department of Materia Medica D.E.I. Faculty of Integrated Medicine Dayalbagh, Agra, Uttar Pradesh, India
Corresponding Author: Dr. Tanupriya Bhardwaj Assistant Professor, department of Materia Medica, D.E.I. Faculty of Integrated Medicine Dayalbagh, Agra, Uttar Pradesh, India

\title{
Homoeopathic management of seasonal influenza
}

\section{Dr. Tanupriya Bhardwaj}

DOI: https://doi.org/10.33545/26164485.2021.v5.i2a.355

\section{Abstract}

This work aims about thorough version of seasonal influenza, and the therapeutic affinity of various homeopathy drugs on it. Influenza is an acute systemic viral infection which primarily affects respiratory tract ${ }^{[1]}$. Homeopathy has a long tradition of being used to treat influenza. So here we are highlighting various therapeutics and their indication on seasonal influenza.

Keywords: Influenza, homoeopathy, Flu, $\mathrm{H}_{1} \mathrm{~N}_{1}$

\section{Introduction}

Influenza is a familiar viral infection primarily affects respiratory system - your nose, throat and lungs. It is caused by influenza A or influenza B virus. Infection is seasonal and variation in haemagglutin and neuraminidase glycoproteins on surface of virus leads to variable intensity each year ${ }^{[1]}$. Seasonal influenza is characterized by a rapid onset of fever, usually dry cough, headache, muscle and joint pain, severe malaise, sore throat and a runny nose. The cough is severe, it lasts for two or more weeks.

\section{Epidemiology}

The agent

1. Influenza viruses belong to Orthomyxoviridae family of viruses ${ }^{[2]}$.

2. Its nucleic acid consists of negtive single stranded RNA.

3. There are 3 Influenza virus types, namely Types A, B, C ${ }^{[2]}$.

4. Types A and B: important for humans contains 8 vRNA segments and type $\mathrm{C}$ contains 7 vRNA segments

5. Type $\mathrm{A}$ is further subdivided into variable combination patterns of their own specific $\mathrm{H}$ or $\mathrm{N}$ proteins (H1N1 or H3N2 etc) ${ }^{[3]}$.

6. Type A viruses having high genetic variety cause greatest morbidity and mortality ${ }^{[3]}$.

7. Seasonal Influenza is caused by Influenza A, HI N 1, H3N2, H2N2, Influenza B etc.

\section{Host factors}

Incidence is higher in

1. young children and those above 65 years ${ }^{[4]}$

2. Health workers;

3. Persons with co-morbid conditions (such a lung disease, heart disease, liver disease, kidney disease, blood disorders, Diabetes) and immuno-compromised persons are at higher risk ${ }^{[4]}$

4. High rate of complications in extremes of age and in co-morbid conditions.

5. A higher risk of severe complications from pandemic (H1N1) 2009 virus infection has also been reported in persons who were obese chiefly in those who are morbidly obese) [4].

\section{Environmental factors}

More incidence during monsoon.

In north, north-west and Central India, the surge in cases usually occurs in winters (January to March)

\section{Mode of Transmission}

Air borne from person-to-person, through large droplets generated during coughing and sneezing. Though the size of infectious droplets are large and usually remain floating in air 
long time and move a short distance therefore airborne is not often considered for spread of disease ${ }^{[5]}$.

- Droplets highly contagious to susceptible persons.

- Indirect contact by touching contaminated object or surface (fomite transmission), close contact (including hand shaking)

\section{Incubation Period}

1- 4 days (typically 2-3 days).

- Viral shedding begins before symptom onset and peaks on day 1 of the symptoms.

- Adults continue to shed virus for 4-6 days, it stops after 6 to 7 days and sometimes after 10 days according to some investigations ${ }^{[6]}$.

- Children and Immuno suppressed/immunecompromised patients: can shed for months.

\section{Period of Communicability}

- From 1 day before to 7 days after the onset of symptoms being the most contagious in first 3-4 days of commencement ${ }^{[7]}$.

- If disease persists for more than 7 days, chances of communicability continue till resolution of disease.

- Children may spread the virus for a longer period ${ }^{[7]}$.

\section{Clinical features ${ }^{[7]}$}

- $\quad$ Sudden, rapid onset of symptoms.

- Fever, chills, body aches, sore throat, non-productive productive cough, runny nose and headache.

- Gastrointestinal symptoms and muscle inflammation: more often in young children.

- Infants can present with a sepsis-like syndrome.

- In immuno-compromised host may only have noticeable coryza and in much older patients can be only present as tiredness cough, confusion and anorexia [8].

- In recent years when $\mathrm{H} 1 \mathrm{~N} 1$ and $\mathrm{H} 3 \mathrm{~N} 2$ virus have co circulated, the latter has caused severe epidemics ${ }^{[9]}$.

\section{Physical Finding}

Fever: rapid onset, up to 400C (410C in children), typically lasting 3 days (up to 4-8 days), gradually diminishing ${ }^{[1,7]}$.

- Face: flushed Skin: hot and moist.

- Eyes: watery, reddened.

- Nose: nasal discharge.

- Ear: Otitis.

- Mucous membranes: hyperaemic.

- Cervical lymphadenopathy: (especially in children).

- Pulmonary examination typically reveals ronchi, wheezes and nonlocalised scattered rales ${ }^{[9]}$.

\section{Course of illness}

Severity varies from symptoms of cold to severe prostration with no major respiratory signs and symptoms, especially within the elderly ${ }^{[8]}$.

- Fever and systemic symptoms classically last 3 days, infrequently 5-8 days, and gradually diminish.

- Cough and weakness can continue for more than 2 weeks.

- Full recovery: 1-2 weeks or longer, especially in the elderly.

\section{Investigations ${ }^{[10]}$}

Routine investigations: haematological, radiological, biochemical and microbiological tests as necessary.

- Confirmation of seasonal influenza (including HIN1) infection:

- Real time RTPCR

- Isolation of the virus in culture or

- Four-fold rise in virus specific neutralizing antibodies.

- Clinical specimens such as nasopharyngeal swab, throat swab, nasal swab, wash or aspirate, and tracheal aspirate for intubated patients.

- The most useful clinically is PCR based molecular probe as this is not only the most sensitive and specific method; it also provides opportunities to identify strain with some specificity ${ }^{[9]}$.

- However Influenza diagnostic test performance can be badly affected by viral genetic and antigenic changes and should be re-assessed yearly ${ }^{[11]}$.

\section{Homoeopathic Remedies Arsenicum album ${ }^{[12]}$}

Arsenic remedy feels chilly and exhausted, along with an great anguish and restlessness, thirsty but often only takes small sips. If the digestive system is involved, symptoms will be nausea with burning pain, gastralgia and offensive stool. Suffocative Catarrah, thin watery excoriating discharge, coryza worse in open air. Patient's headache relieved by cold other symptoms are worse by cold.

\section{Ferrum phosphoricum ${ }^{[12]}$}

Low-grade fever with prostration, also have tendency of nose bleeding and ear pain. All catarrahal and inflammatory fevers, first stage.

\section{Belladonna ${ }^{[13]}$}

It relieves high fever of sudden onset, head hot and painful. Patient is hypersensitive to noise, drafts of air and bright light.

\section{Eupatorium perfoliatum ${ }^{[13]}$}

It relieves body aches and bone pain along with flu. Great prostration in epidemic influenza, chest sore with painfull soreness of eyeballs.

\section{Bryonia alba ${ }^{[14]}$}

Indicated in nasal catarrh with either great dryness of mucous memebrane of nose or when discharge is yellow and thick. High fever with body aches improved by remaining at a place.However it is not given in catarrhs without any bowel symptoms.

\section{Gelsemium $^{[15]}$}

It relieves symptoms like fever, dull headache at base of brain, dizziness with blurred vision and general weakness.

\section{Nux vomica ${ }^{[16]}$}

Person having coryza with sneezing, attacks comes after eating and in morning. Dry coryza with soreness of abdomen. A person often very irritable, impatient, ardent character feeling worse from exertion and worse from being cold in any way. 


\section{Rhus toxicodendron ${ }^{[17]}$}

Patient is restless in fever, Continuous movement to find a comfortable position and to relieve the symptoms while experience aggravation in starting a movement.

\section{Aconitum napellus ${ }^{[17]}$}

It relieves high fever of sudden and violent onset, Skin is dry and hot face.

\section{Sulphur ${ }^{[17]}$}

Indicated when flu is very long-lasting or has some lingering symptoms. Hot or burning quality is a strong indication of sulphur. Patient feels hot with perspiration increased, low fever and reddish mucous membranes. Heat aggravates the symptoms and feels worse after bath.

\section{Apis mellifica ${ }^{[18]}$ \\ It relieves dry fever which alternates with sweating, facial flushing, sore throat with swollen tonsils. Pain extends to the ears, and the eyelids can be swollen. Cold applications brings relief. In fever thirst is usually low and chill about $3 \mathrm{pm}$.}

\section{Phosphorus ${ }^{[18]}$}

It relieves fever with an easily-flushing face, coryza fluent especially during day, alternating fluent and dry. Rawness and scraping in pharynx worse in evening and hawking in morning.

\section{Conclusion}

This article provides us concept of influenza and the details of various homoeopathic medicines recommended for it (by the concept of individualization) which can manage seasonal influenza safely without any side effects.

\section{References}

1. Ralston, Stuart H. et al., Davidson's principles and practice of medicine, Elsevier, Edinburgh 240, 241.

2. Bansal, Mohan, Diseases of ear nose \&throat with head \& neck surgery, Jaypee, New Delhi, 103.

3. Moghadami M. A Narrative review of influenza: A seasonal and pandemic diseas. IJMS 2017;42(1):2-4.

4. World Health Organization (WHO) [Internet] Clinical management of human infection with pandemic (H1N1) 2009. [Revised guidance [cited 2014 November 18]]. Availablefrom: http://www.who.int/csr/resources/public ations/swineflu/clinical_management_h1n1.pdf.pg 2

5. Brankston G, Gitterman L, Hirji Z, Lemieux C, Gardam M. Transmission of influenza A in human beings. Lancet Infect Dis 2007;7:257-65.

6. Reddy E, Sharma PK, Raj PP. A clinical study on effect of Plantago in gingivitis by assessing bleeding and plaque index. Doi: 10.1016/S1473-3099(07)700294. [PubMed]

7. Wong BC, Lee N, Li Y, Chan PK, Qiu H, Luo Z et al. Possible role of aerosol transmission in a hospital outbreak of influenza. Clin Infect Dis 2010;51:1176-83. Doi: 10.1086/656743.

8. Key facts About Influenza [Internet]. Centers for Disease Control and Prevention, [updated 2019, 13. cited 2020 Oct 1]. Available from https://www.cdc.gov/flu/about/keyfacts.htm?CDC_AA _refVal=https $\% 3 \mathrm{~A} \% 2 \mathrm{~F} \% 2 \mathrm{Fwww} . \mathrm{cdc}$. gov $\% 2 \mathrm{Fflu} \% 2 \mathrm{Fk}$ eyfacts.htm

9. Walsh EE, Cox C, Falsey AR. Clinical features of influenza A virus infection in older hospitalized persons. J Am Geriatr Soc 2002;50:1498-1503. Doi: 10.1046/j.1532-5415.2002.50404.x. [PubMed]

10. Jameson J, Longo D et al., Harrison's principle of internal medicine, $20^{\text {th }}$ edition. The McGraw-Hill Companies, New York, 2018, 1386-87.

11. Overview of influenza testing [Internet].Centers for Disease Control and Prevention, [updated 2020 Aug 3; cited 2020 Oct 31].

12. Marie Lousy Landry.Diagnostic tests for influenza infection. PMID. 2011;23(1):91-7. Doi: 10.1097/MOP.0b013e328341ebd9. https://pubmed.ncbi.nlm.nih.gov/21150446/

13. William Boericke, Boericke's new manual of homoepathic materia medica with repertory, B. jain Publishers, New Delhi, Edn 2016;72-74,254-255.

14. Allen HC, Allen Keynotes, B Jain Publishers, New Delhi, Edn 2017;129:55-57.

15. Farrington EA. Clinical Materia Medica,Indian Books\& Periodicals pubishers. Tanuja BM. Text Book of Medicine. New Delhi. Edn 2013, 294.

16. Nash EB. Leaders in Homoeopathic Therapeutics, B. Jain Publishers, New Delhi, Edn 2016, 211.

17. WMH Burt. Physiological Materia Medica, B.Jain Publishers, Noida, Edn 2016, 661-664.

18. Influenza. (Homeopathy) [Internet]. Peace Health, [ updated 2012 0ct 31; cited 2021 Jan 20]; Available from https://www.peacehealth.org/medicaltopics/id/hn-2236006

19. Hering C. Condensed Materia Medica, B jain Publishers, Noida, Edn 2016, 98, 102, 737, 743. 